\title{
Discharge simulations performed with a hydrological model using bias corrected regional climate model input
}

\author{
S. C. van Pelt ${ }^{1}$, P. Kabat ${ }^{1}$, H. W. ter Maat ${ }^{1}$, B. J. J. M. van den Hurk $^{2}$, and A. H. Weerts ${ }^{3}$ \\ ${ }^{1}$ Earth System Science and Climate Change Group, Wageningen UR, Droevendaalsesteeg 4, 6708 PB Wageningen, \\ The Netherlands \\ ${ }^{2}$ KNMI, P.O. Box 201, 3730 AE De Bilt, The Netherlands \\ ${ }^{3}$ Deltares, Rotterdamseweg 185, 2629 HD Delft, The Netherlands
}

Received: 3 June 2009 - Published in Hydrol. Earth Syst. Sci. Discuss.: 29 June 2009

Revised: 9 November 2009 - Accepted: 25 November 2009 - Published: 11 December 2009

\begin{abstract}
Studies have demonstrated that precipitation on Northern Hemisphere mid-latitudes has increased in the last decades and that it is likely that this trend will continue. This will have an influence on discharge of the river Meuse. The use of bias correction methods is important when the effect of precipitation change on river discharge is studied. The objective of this paper is to investigate the effect of using two different bias correction methods on output from a Regional Climate Model (RCM) simulation. In this study a Regional Atmospheric Climate Model (RACMO2) run is used, forced by ECHAM5/MPIOM under the condition of the SRES-A1B emission scenario, with a $25 \mathrm{~km}$ horizontal resolution. The RACMO2 runs contain a systematic precipitation bias on which two bias correction methods are applied. The first method corrects for the wet day fraction and wet day average (WD bias correction) and the second method corrects for the mean and coefficient of variance (MV bias correction). The WD bias correction initially corrects well for the average, but it appears that too many successive precipitation days were removed with this correction. The second method performed less well on average bias correction, but the temporal precipitation pattern was better. Subsequently, the discharge was calculated by using RACMO2 output as forcing to the HBV96 hydrological model. A large difference was found between the simulated discharge of the uncorrected RACMO2 run, the WD bias corrected run and the MV bias corrected run. These results show the importance of an appropriate bias correction.
\end{abstract}

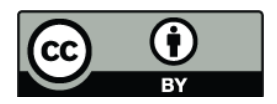

Correspondence to: S. C. van Pelt (saskia.vanpelt@wur.nl)

\section{Introduction}

During the last few decades the world has become subject to a changing climate unprecedented in the last millennia. Temperature increase and other climate related changes will have large global impacts. According to IPCC (IPCC, 2007), winter precipitation is projected to increase over Northwest Europe. This applies to the mean, but also to the increase in frequency and severity of extreme precipitation events. For the Netherlands the KNMI '06 climate change scenarios foresee wetter winters and increasing extreme precipitation amounts (van den Hurk et al., 2006).

A large fraction of precipitation received by river basins is buffered in natural reservoirs, like soils, aquifers, lakes and artificial reservoirs from which water is released only slowly. In a temperate climate such as is prevailing over the Meuse and Rhine basin, this generally results in a continuous flow of water. However, exceptional meteorological conditions can cause floods and longer periods of low flows (de Wit et al., 2001). Occurrences in the past indicate that it is important to monitor and manage these rivers. As the Meuse is an almost purely rain-fed system, the seasonal and interannual variability of the hydrological regime of this river is more pronounced than that of the Rhine. It is also more likely to react stronger to the effect of global climate change (Uijlenhoet et al., 2001). Another aspect, which increases the variability of the system, is the substrate characteristics of the Meuse. The restricted dimension of the floodplain of the Ardennes Massif offers little room for natural flood retention areas, so water moves downstream relatively quickly.

By doing a statistical analysis of long observation records (1911-2002) for the Meuse basin, it was shown that the frequencies of wet days hardly have changed, but the associated precipitation amounts have significantly increased since 1980 (Tu et al., 2005b). An average increase in extreme

Published by Copernicus Publications on behalf of the European Geosciences Union. 
precipitation of $18 \%$ has been simulated by regional climate models over the recent history. The uncertainty of model simulations is significantly larger than the observed change. As different models show the same trends (e.g. higher temperatures and more extreme precipitation) and there are no indications that these trends will change by abrupt climate change, the uncertainty does not completely overshadow the simulated change (Booij, 2002). From recent simulations with (regional) climate models it appears that a large number of models, especially in summer, show dryness as a consequence of a strong hydrological feedback between the land surface and the atmosphere. This means that in these models the precipitation declines, which results in dehydration of the soil (Smits et al., 2004).

Increased precipitation will lead to more frequent high flow conditions. This trend started in the second half of the 20th century, where an increased flooding probability has been observed (Pfister et al., 2004) and will probably continue during the 21st century (de Wit, 2001; de Wit et al., 2007b). A significant increase since the beginning of the 80 s of the 20th century has been demonstrated statistically (Tu et al., 2005a) This holds for the annual extremes, the winter high tides and discharges larger than $800 \mathrm{~m}^{3} \mathrm{~s}^{-1}$.

De Wit (2001) states that simulations performed with a number of Global Climate Models (GCMs) suggest an increase in temperature, an increase in winter precipitation and a decrease in summer precipitation in the Meuse basin by the end of the 21 st century. This results in a small decrease of the average discharge and a small increase of discharge variability and extreme discharges (Booij, 2005). It should be noted that simulations demonstrate that an extreme peak on the Meuse follows from a long period of moderate wet days instead of one or two extreme wet days (Aalders et al., 2004).

Also Regional Climate Model (RCM) simulations, driven by a range of GCM projections, indicate a future with wetter winters and drier summers (de Wit et al., 2007a). On the occurrence of low flows in summer less research has been done. De Wit et al. (2007a) studied the possible impact of climate change on the occurrence of low-flow generating meteorological conditions and on the impact of climate change on low-flows with HBV-model simulations. In addition, De Wit et al. (2007a) concluded that decrease of summer discharge does not necessarily mean that critical summer low-flows will become more severe and frequent. It was also found that the HBV-model, with a generally good performance, did not accurately simulate critical low-flows of the Meuse. So far, there is no ground to conclude that extreme low flows will occur more frequently (Warmerdam and de Wit, 2001; de Wit et al., 2001). The EU PRUDENCE project (Christensen and Christensen, 2007) coordinated several studies on regional climate change projection for European river basins. The results of these studies showed similar results with a possible decrease of discharge in summer and increase of discharge in winter (Graham et al., 2007; Jacob et al., 2007; Hagemann and Jacob, 2007).
This paper will present the results of simulations with a new high $(25 \mathrm{~km})$ resolution Regional Atmospheric Climate Model (RACMO2). It uses a higher resolution than in earlier studies (Leander and Buishand, 2007; Leander et al., 2008; de Wit et al., 2007a), presumably resolving the average and extreme discharges at the basin outlet better (Booij, 2005).

The main focus of this paper is the use of bias correction methods. Bias corrections are applied to correct for systematic precipitation errors compared to observations. Two nonlinear bias correction methods are explored. Linear corrections for the bias in the mean precipitation lead to an underestimation of large quantiles of their distribution (Leander and Buishand, 2007). A relatively simple nonlinear correction adjusting both the biases in the mean and variability produces a better reproduction of observed extreme daily and multi-day precipitation amount than the commonly used linear scaling correction. This also results in more realistic discharge extremes, suggesting that a correct representation of the variability of precipitation is important for the simulation of extreme flood quantiles (Leander and Buishand, 2007). In this paper two different bias correction methods will be applied to the RCM precipitation. Subsequently, RCM output is used to drive the hydrological model HBV for the Meuse basin to investigate the effect of the bias corrections on the simulated discharges for present day and future climate conditions.

\section{Meuse basin}

The Netherlands is one of the smaller, highly populated countries in Europe. It forms the delta of a number of international river basins, including the Rhine and the Meuse. These rivers are used for multiple purposes and have contributed to the prosperous development of Northwest Europe. The Meuse originates in France and flows through Belgium. Via the Netherlands it drains into the North-Sea. The Meuse is rain-fed and has a length of approximately $875 \mathrm{~km}$. The basin has an area of $36000 \mathrm{~km}^{2}$, and covers parts of France, Belgium, Luxembourg, Germany and the Netherlands. Northwest Europe has a temperate climate, with frequent eastward moving Atlantic depressions, which results in a mean annual precipitation over the Meuse of $950 \mathrm{~mm} \mathrm{yr}^{-1}$. The spatial distribution patterns of rainfall in the Meuse basin are mainly the result of differences in altitude. The rainfall is highest in the Ardennes Massif $\left(1500 \mathrm{~mm} \mathrm{yr}^{-1}\right)$ and lowest in the lowlands (Pfister et al., 2004). The mean discharge of the Meuse at Liege for summer half-year is $146 \mathrm{~m}^{3} \mathrm{~s}^{-1}$. In summer, flows are low and the evaporation rates are high. In the winter, it is $406 \mathrm{~m}^{3} \mathrm{~s}^{-1}$ with evaporation rates at the lowest level. The annual mean discharge for the Meuse at Liege is $276 \mathrm{~m}^{3} \mathrm{~s}^{-1}$ (Ashagrie et al., 2006). The Meuse has a relative fast response to rainfall, so it is relatively sensitive to both floods and droughts. The river flood waves mainly occur during the winter half-year. 


\section{Data and methodology}

In this study the KNMI model RACMO2 (Lenderink et al., 2003 ) is used. The model was developed over the past few years and is the second version of a regional atmospheric climate model developed by KNMI. RACMO2 has been applied in the framework of PRUDENCE (Prediction of Regional scenarios and Uncertainties for Defining EuropeaN Climate change risks and Effects) and ENSEMBLES (Lorenz and Jacob, 2008). The RACMO2 run used in this study is forced with output from a transient (1950-2100) run conducted with the coupled atmosphere/ocean GCM ECHAM5/MPIOM (member 3) (Jungclaus et al., 2006; Roeckner et al., 2003), under the condition of the SRESA1B emission scenario. ECHAM5/MPIOM is the fifth generation atmospheric general circulation model developed at the Max Planck Institute for Meteorology (Roeckner et al., 2003). ECHAM5 is coupled to the ocean model MPIOM, which is based on the previous HOPE model. (Jungclaus et al., 2006). The horizontal resolution of RACMO2 is approximately $25 \times 25 \mathrm{~km}$.

The changes in river discharge are estimated using both the direct and bias corrected output from RACMO2 to force the hydrological model. In studies using RCMs, systematic biases are present, which result in under - or overestimation in precipitation or discharge. Leander et al. (2007) found that the simulated precipitation differed systematically from the observed precipitation. Both the temperature and the precipitation data created by RACMO 2 are bias corrected in this paper. Temperature data are corrected using one method, and two bias correction methods are used to correct the precipitation data. The first bias correction method is developed by Leander and Buishand (2007) for the river Meuse. The second bias correction method is developed by Bakker (2009). Until now this latter method has only been applied to the Rhine river basin. The section below gives an overview of the correction methods and the hydrological model used.

\subsection{The HBV model}

The HBV model (Hydrologiska Byråns Vattenbalansavdelning; Hydrological Bureau Water balance-section; Bergström and Forsman, 1973) is, especially in Nordic countries, often used to simulate discharge response to a changing climate (Bergström et al., 2001).

The HBV model is a rainfall-runoff model, which includes conceptual numerical descriptions of hydrological processes at the catchment scale. It was originally developed by the Swedish Meteorological and Hydrological Institute (SMHI) in the early 70 s to assist hydropower operations. An advantage of the HBV model is the large number of applications in more than 40 countries world-wide. Its applications cover basins in different climatological and geographical regions, ranging in size from less than one to more than $1792000 \mathrm{~km}^{2}$

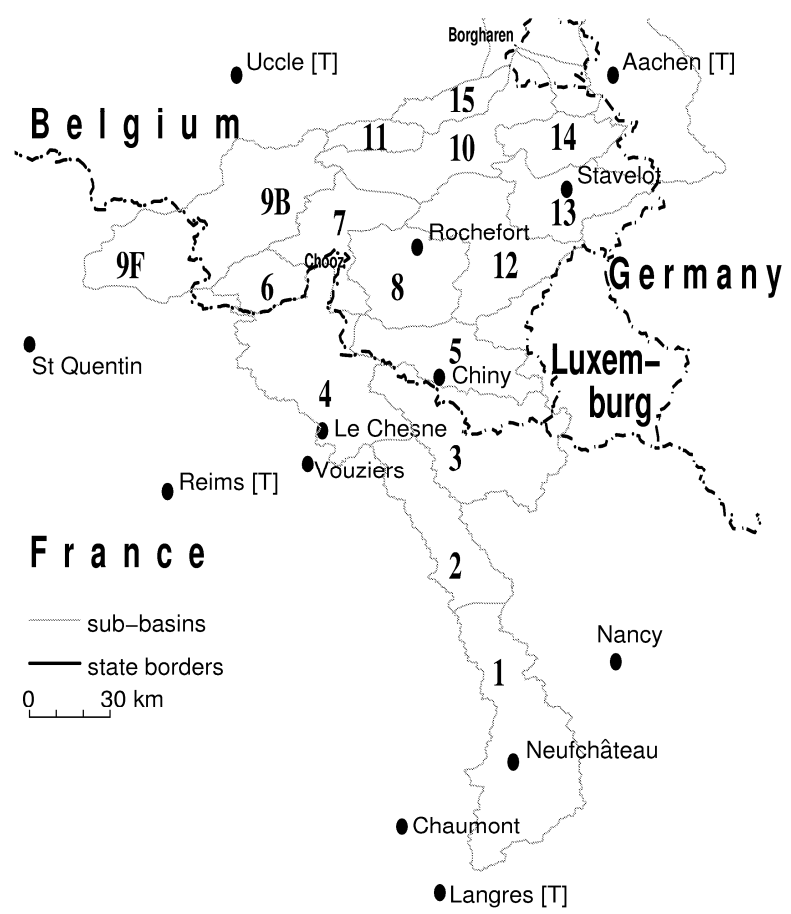

Fig. 1. Meuse Basin and observation stations.

(Bergström, 1995; Bergström and Carlsson, 1994). In comparison, the Meuse basin has a surface area of $36000 \mathrm{~km}^{2}$.

The model consists of subroutines for meteorological interpolation, snow accumulation and melt, evapotranspiration estimation, soil moisture, runoff generation and a simple routing procedure between sub-basins considering lakes. The processes infiltration excess overland flow, saturation excess overland flow and subsurface storm flow are represented by one fast flow component. Several sub-basins can be combined to obtain the appropriate spatial scale (Booij, 2005).

The model used for this study is the HBV-96. For hydrological simulations, the Meuse basin is divided in 15 subbasins (Fig. 1). RACMO2 at $25 \mathrm{~km}$ resolution covers the basin by 15 grid boxes. The simulated area-average precipitation for each of the sub-basins was obtained as a weighted average over the grid boxes covering the sub basin. The weights were determined as the fraction of the sub basin area falling within a specific grid (Leander and Buishand, 2007). The HBV model is run with both bias corrected data, the uncorrected dataset and observed data. The daily input for the HBV model is temperature $(T)$, precipitation $(P)$ and potential evapotranspiration $(P E T)$. These values are simulated by RACMO2, or observed. The model is run for the period 1951-2100 and different time-slices will be used in the analysis of the results. 


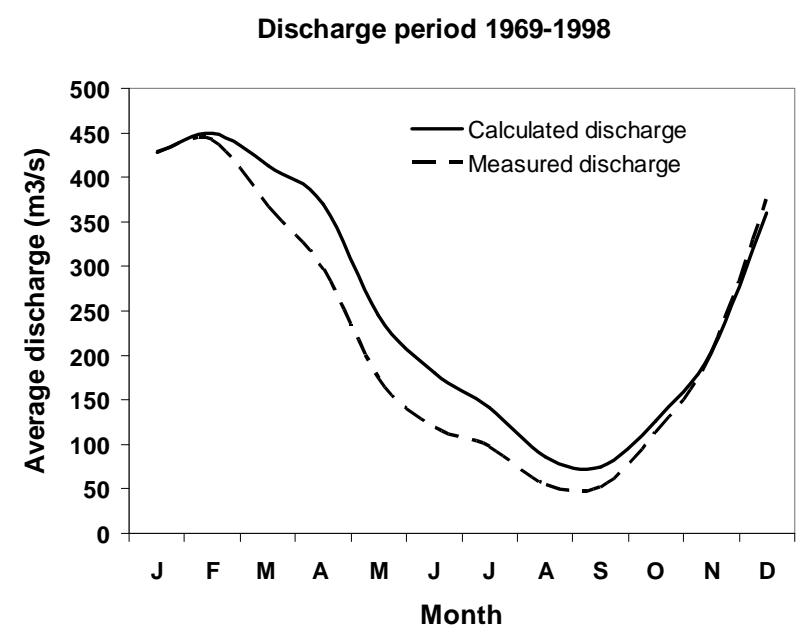

Fig. 2. Monthly average simulated discharge with use of observed temperature and precipitation compared with measured discharge at Borgharen for the period 1969-1998.

\subsubsection{Performance of HBV model}

The original calibration of the HBV model by the Meuse was carried out by Booij (2005). For more information on the calibration and HBV parameters see Leander et al. (2005) and Booij (2005). In order to assess the performance of the HBV model, a run with observed temperature and precipitation data was executed. The output was compared to the measured river discharge data. The results are shown in Fig. 2.

As can be seen in Fig. 2 the measured discharge is slightly lower than the simulated discharge for nearly every month. The cause of this deviation is not known and may have multiple sources like the stage-discharge relationship, model calibration and the limited number of temperature and precipitation observations.

Table 1 gives more insight in the performance of the HBV model. For instance, the number of days with a discharge above $1500 \mathrm{~m}^{3} \mathrm{~s}^{-1}$ reflects the risk of flood events (van Schrojenstein Lantman, 2004). Values below $60 \mathrm{~m}^{3} \mathrm{~s}^{-1}$ induce problems for shipping and other water supply functions (de Wit et al., 2007a). It can also be seen that discharge is overestimated during spring and summer. The observed value of the summer half-year mean is much higher than the measured value. The number of days below $60 \mathrm{~m}^{3} \mathrm{~s}^{-1}$ is almost twice as high for the measured values. This confirms that the HBV model has difficulties in simulating low flows.

\subsection{Bias correction methods for RACMO2 data}

\subsubsection{Temperature}

For temperature, observed records from the Meuse basin were available from the period 1969-1998. See Fig. 1 for locations of observation stations. Thirty years of output during
Table 1. Statistics of modeled and observed values over the period 1969-1998 at Borgharen. HBV-CTL values are model calculations using observed temperature and precipitation records.

\begin{tabular}{lll}
\hline & $\begin{array}{l}\text { Modeled } \\
\text { values } \\
\text { (HBV-CTL) }\end{array}$ & $\begin{array}{l}\text { Observed } \\
\text { values }\end{array}$ \\
\hline Annual mean $\left(\mathrm{m}^{3} / \mathrm{s}^{-1}\right)$ & 257 & 227 \\
No of days $\geq 1500 \mathrm{~m}^{3} \mathrm{~s}^{-1}(\%)$ & 0.4 & 0.5 \\
No of days $800<>1500 \mathrm{~m}^{3} \mathrm{~s}^{-1}(\%)$ & 4.6 & 4.2 \\
No of days $\leq 60 \mathrm{~m}^{3} \mathrm{~s}^{-1}(\%)$ & 15.7 & 29.0 \\
Maximum discharge $\left(\mathrm{m}^{3} / \mathrm{s}^{-1}\right)$ & 2837 & 2959 \\
Minimum discharge $\left(\mathrm{m}^{3} / \mathrm{s}^{-1}\right)$ & 8.5 & 0 \\
Winter half-year mean $\left(\mathrm{m}^{3} / \mathrm{s}^{-1}\right)$ & 329 & 320 \\
Summer half-year mean $\left(\mathrm{m}^{3} / \mathrm{s}^{-1}\right)$ & 183 & 132 \\
\hline
\end{tabular}

the control period (arbitrarily taken to be the same years 1969-1998 as for the observations) of this run was compared to the observed values and showed a systematic bias. A nonlinear bias correction was applied involving shifting and scaling to adjust the mean and variance.

The corrected temperature $T^{*}$ can be obtained by:

$T^{*}=\bar{T}_{m}+\left(\sigma \bar{T}_{o, s} / \sigma \bar{T}_{m, a}\right)\left(\bar{T}_{m}-T_{m}\right)+\left(\bar{T}_{o, s}-\bar{T}_{m, a}\right)$

where $T_{m}$ is the uncorrected daily temperature from RACMO2, $T_{o, s}$ is the average of observed temperatures and $T_{m, a}$ is the corresponding basin average temperature from RACMO2. An overbar denotes the 30-year average, subscript $o$ the observed values, $m$ the modeled values and $\sigma$ the standard deviation

The 30-year average and the standard deviation of the temperature data were separately determined for each five-day period of the year as the ratio between the average observed and $\mathrm{RACMO} 2$ temperature in a window including the 30 days before and after the considered five-day period (Leander and Buishand, 2007).

\subsubsection{Precipitation}

For precipitation, observational records were available from the period 1969-1998 and a similar control period was taken from the RACMO2 data. The precipitation bias precipitation was corrected using two different methods. In the first method, a two-step correction was executed to correct for the wet day frequency $\left(F_{\text {wet }}\right)$ and the wet day average $\left(M_{\text {wet }}\right)$, see also Table 2 and te Linde et al. (2009). A correction for $F_{\text {wet }}$ is carried out by eliminating or creating wet days. $M_{\text {wet }}$ is corrected by decreasing of increasing the wet day average. For each month the wet days are ranked according to the precipitation amount. Selection of wet days to be removed makes use of this ranking by demanding that the distribution of wet day precipitation intensity changes as little as possible. Another condition is that wet days are only deleted if 
Table 2. Statistics of both correction methods. OBS means observed values for the period 1969-1998. St. Dev. is standard deviation and $C V$ means coefficient of variation. $M_{\text {wet }}$ is the average amount of precipitation on days with $\geq 0.3$ mm precipitation. $F_{\text {wet }}$ is the wet day frequency which is the percentage of days with an amount of $\geq 0.3 \mathrm{~mm}$ precipitation. The statistics are averages over all sub-basins. Winter half-year is from October to March, summer half-year is from April to September. No-corr means uncorrected RACMO2 data. WD or MV refer to the bias correction methods applied to the RACMO2 data.

\begin{tabular}{lcccccccc}
\hline 1969-1998 & $\begin{array}{c}\text { OBS } \\
\text { Winter }\end{array}$ & $\begin{array}{c}\text { No- } \\
\text { corr }\end{array}$ & WD & MV & $\begin{array}{c}\text { OBS } \\
\text { Summer }\end{array}$ & $\begin{array}{l}\text { No- } \\
\text { corr }\end{array}$ & WD & MV \\
\hline Average & 2.78 & 3.60 & 2.79 & 2.77 & 2.43 & 2.81 & 2.44 & 2.42 \\
St. Dev & 4.78 & 4.89 & 4.61 & 4.77 & 4.42 & 4.55 & 4.51 & 4.42 \\
$C V$ & 1.73 & 1.36 & 1.66 & 1.72 & 1.82 & 1.63 & 1.85 & 1.84 \\
$M_{\text {wet }}[\geq 0.3]$ & 4.97 & 4.93 & 4.99 & 4.49 & 4.85 & 4.66 & 4.90 & 4.32 \\
$F_{\text {wet }}(\%)[\leq 0.3]$ & 55.3 & 72.2 & 55.2 & 61.1 & 49.9 & 59.8 & 50.1 & 55.7 \\
\hline
\end{tabular}

precipitation on days before or after the particular day is less than a threshold value. As the uncorrected precipitation data were overestimating the precipitation, introducing new wet days did hardly occur. In the remainder of this paper this procedure will be referred to as the "Wet Day (WD) bias correction".

The second correction method uses a non-linear method which corrects the coefficient of variation $(C V)$ as well as the mean. Each daily amount of precipitation $P$ is transformed to a new amount $P^{*}$ using:

$P^{*}=a P^{b}$

The parameters $a$ and $b$ were estimated for each five-day period using a similar running time filter as for temperature. The value of $b$ is determined such that the $C V$ of the corrected daily precipitation matches that of the observed daily precipitation. $a$ is calculated subsequently in order to match the mean of the corrected values to the observed mean. This bias correction will be referred to as the "Mean Variance (MV) bias correction". The method is also described by Leander $(2007,2008)$.

Daily values of Potential Evapotranspiration (PET) for the RACMO2 run were calculated using daily values of $P E T$ for Belgian sub-basins. Similar values for French basins were not available and therefore the area-weighted average of the Belgian basins was used for this part. PET was derived for each of the sub-basins from the daily temperature $T$ using the relation:

$P E T=\left[1+\alpha_{o}\left(T-\bar{T}_{o}\right)\right] \overline{P E T}_{o}$

With $\bar{T}_{o}$ the mean observed temperature $\left({ }^{\circ} \mathrm{C}\right)$ and $\overline{P E T}_{o}$ the mean observed PET $\left(\mathrm{mm} \mathrm{day}^{-1}\right)$ for calendar month $\mathrm{m}$ in the period 1969-1998. The proportionality constant $\alpha_{o}$ was determined for each calendar month by means of a regression of the observed values of PET for the Belgian part of the basin on the observed daily temperatures (Leander and Buishand, 2007). The PET calculated with Eq. (3) is used when HBV is forced with the RCM data.

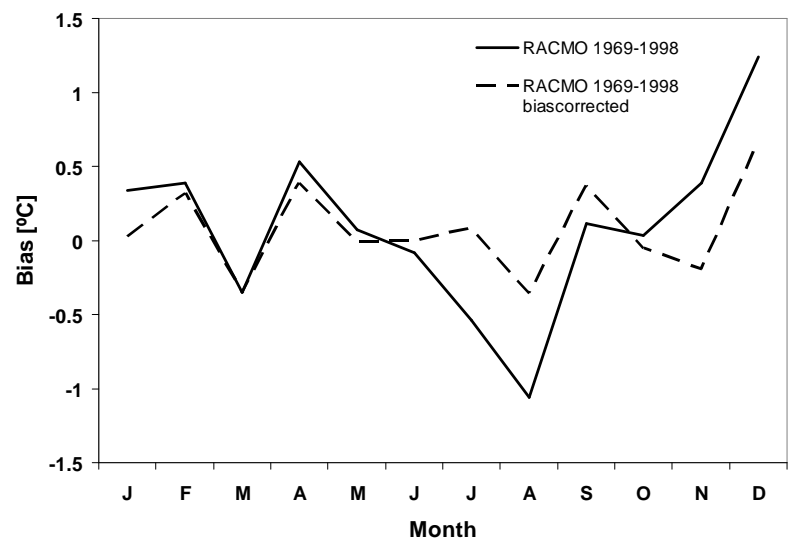

Fig. 3. Absolute temperature bias of RACMO2 data compared to observed data for the period 1969-1998, before and after bias correction. The bias is shown per month, averaged over all 15 sub basin and 30-years.

\section{Result of bias corrections}

\subsection{Temperature}

Bias corrections for temperature were performed on the RACMO2 data according to the methodology described in the previous section. The corrections are performed on each basin separately and were averaged for all 15 sub-basins. Figure 3 shows monthly averages for the period 1969-1998 of the uncorrected and bias corrected temperature data for the Meuse basin.

Figure 3 shows that the bias of the uncorrected data set is quite large, up to more than one degree in August and December. The bias is very variable between months. After correction the bias is reduced. The average reduction of the bias is $45 \%$ and especially the large biases are reduced, together with a decrease in variability. The impact of further temperature bias reductions on simulated extreme flows is probably low (Leander et al., 2008). 


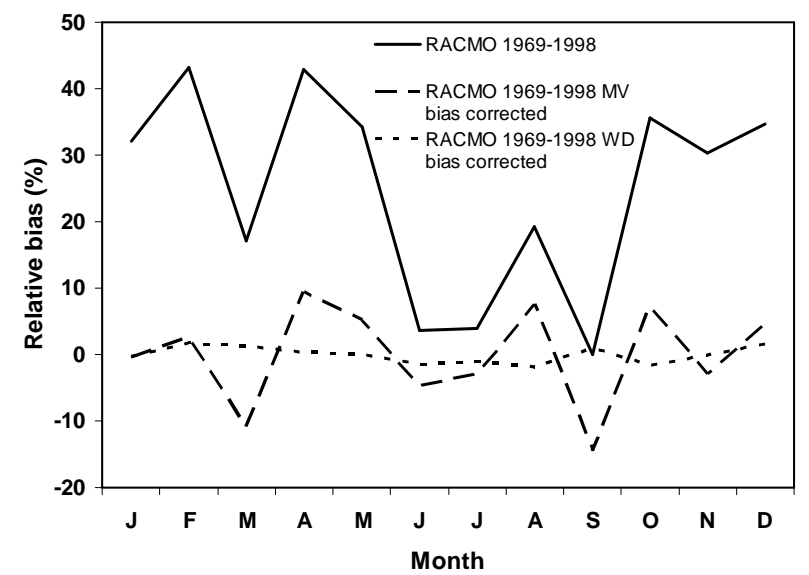

Fig. 4. Relative precipitation bias of RACMO2 data compared to the observed data for the period 1969-1998, before and after bias corrections. The bias is shown per month, averaged over all 15 subbasins and 30-years.

\subsection{Precipitation}

For precipitation data two different bias correction methods were applied as described before. The corrections were performed on each sub basin and subsequently averaged for all basins. All series shown are corrected for the period 19691998.

In Fig. 4 it is shown that the precipitation bias before correction is highly variable and overall quite large, with an average bias of around $25 \%$. In summer the bias is lower than in winter, spring and fall.

The WD correction reduces the bias largely. While the original bias varied between almost zero and $43 \%$, the corrected data show a consistently low average bias of $1 \%$. It seems that this correction method is very well capable of reducing the bias. The MV bias correction method shows more variability and the most remaining bias, with an average of $6 \%$. This is still a large reduction in comparison with the original average bias of $25 \%$.

The bias varies somewhat across the sub-basins. The standard deviation of precipitation using the MV bias correction method is $3.2 \%$, for the WD bias correction method $6.0 \%$ and for the uncorrected RACMO run $19.5 \%$. This indicates that the precipitation spread between the basins of the uncorrected RACMO run is much larger than for the bias corrected runs. The result is not influenced by one basin in particular. For the WD method, one basin does have extra influence because the bias of this basin is significantly larger than for the other basins. This basin (no. 11) is a basin with high precipitation amounts.

Table 2 gives more information about the bias correction methods. Statistics of daily precipitation are shown for comparison of both methods with the uncorrected data. A distinction is made between winter and summer half-year. The

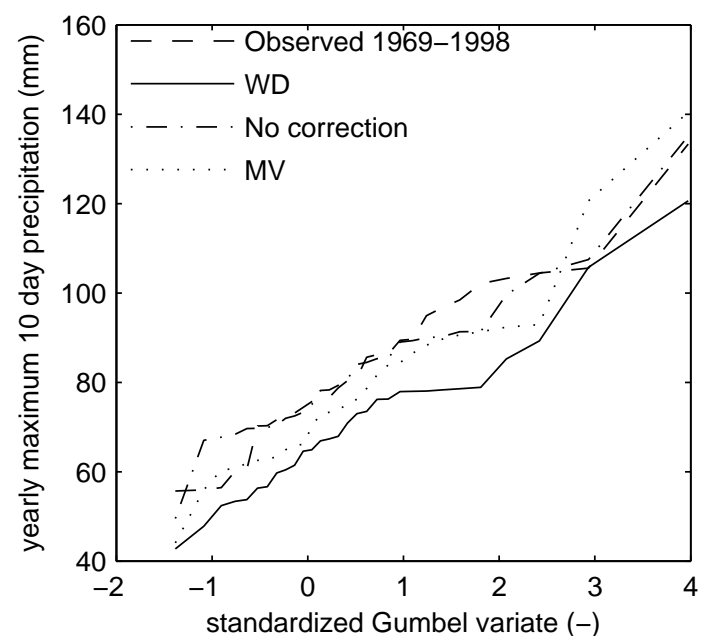

Fig. 5. Gumbel plot with ten-day precipitation amounts. Both observed and modeled values are shown, including RACMO2 data with no bias correction, WD bias correction and MV bias correction. All data refer to the period 1969-1998.

coefficient of variation $(C V)$ is calculated as the ratio between the standard deviation (St. Dev) and the mean.

The differences between observed values (OBS) and the RACMO2 control uncorrected data for winter half-year are larger than the differences for the summer half-year. Again the reason for these smaller differences in summer could be that the total amount of precipitation and the extremes are smaller in this period. Table 2 shows that RACMO2 overestimates the amount of precipitation in all seasons. $M_{\text {wet }}$ is estimated quite well by uncorrected RACMO2 data, while $F_{\text {wet }}$ is overestimated for both winter and summer half-year (see also Fig. 4). It means that the simulated number of wet days is too large, while the average rainfall on these wet days is estimated fairly well. After both bias correction methods the average values are corresponding much better with observed winter and summer values. The two methods provide virtually similar corrected values. The standard deviation and coefficient of variation $(C V)$ are estimated better by the MV method, but also the WD method results in a reduced $C V$. The $M_{\text {wet }}$ and $F_{\text {wet }}$ are clearly estimated better by the WD bias correction method. This is not very remarkable, because the WD bias correction is aimed to produce correct values of $M_{\text {wet }}$ and $F_{\text {wet }}$.

As mentioned in the introduction, extremes in discharge are often preceded by multiple days of heavy rainfall. A realistic simulation should represent this temporal signature. To check whether this is the case, the yearly maxima of the tenday precipitation totals are calculated and displayed for both bias correction methods and the observed rainfall in Fig. 5 as function of the reduced Gumbel variate (a logistic cumulative distribution of probability). The Gumbel distribution is a special case of a Generalized Extreme Value Distribution 


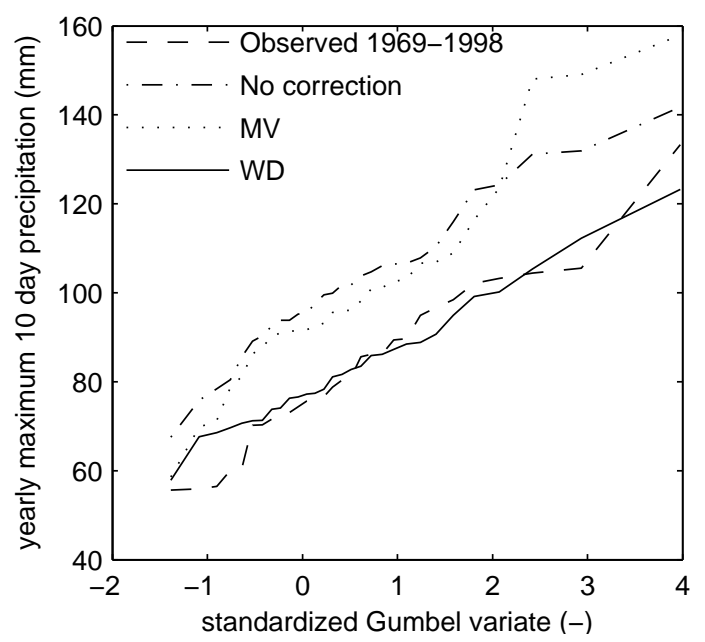

Fig. 6. As Fig. 5, for the scenario period 2071-2100.

$(\mathrm{GEV})$. In current river management practices in the Netherlands it is used to estimate the design discharge (Diermanse, 2004; de Wit and Buishand, 2007).

Figure 5 shows that the WD bias correction gives substantially lower results than the observed data. The uncorrected model output and MV bias correction resemble the observed data set better. This graph shows that the WD bias correction reduces the number of successive rainy days, which are generally responsible for high discharge levels. The WD bias correction produces less high flood peaks which has an impact on modelled future extreme discharges. Figure 6 shows the distribution of annual maxima obtained with uncorrected and bias-corrected RACMO2 for the scenario period 20712100 compared to the observed distribution. The MV bias corrected data simulates increase of the number of successive rainy days for the scenario period than present in the observed data. This implies that more high discharges will be simulated by the HBV model.

Figure 7 shows the relative change in the annual cycle of precipitation between the control period and the end of the 21 st century using both bias correction methods. The data are basin and monthly averaged. For the end of this century it is projected that the winter precipitation will increase and the summer period will be drier. The average change in summer (April - September) is $-10 \%$ for the WD bias correction method and $-7 \%$ for the MV bias correction method. The average change in winter is $+19 \%$ for WD and $+29 \%$ for the MV method. The summer change is fairly similar for both corrections, but the MV bias correction shows a much larger average change for the winter period. This is probably related to the wet day fraction corrected by WD and the small change of the mean precipitation on wet days.

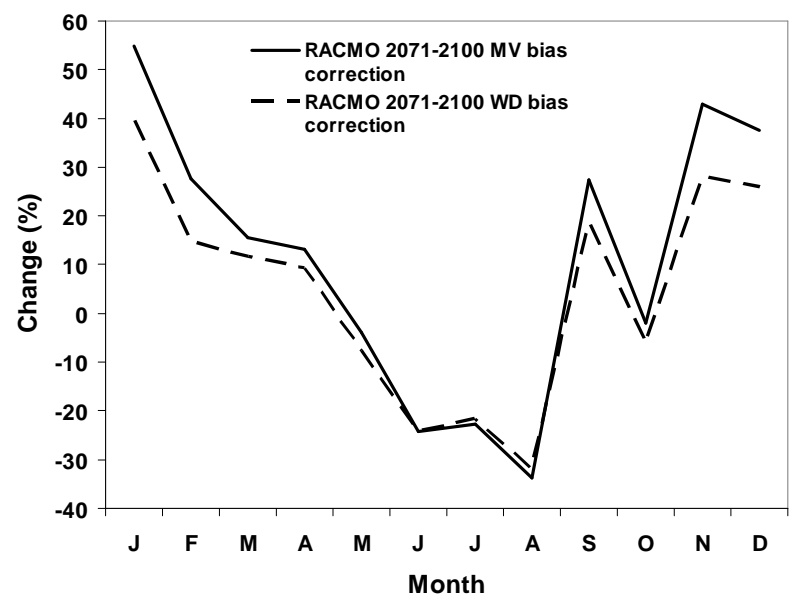

Fig. 7. Relative change of precipitation in the Meuse basin. The simulated scenario period 2071-2100 of RACMO2 MV and WD bias corrections is compared to the RACMO2 control period 19691998.

\section{Results HBV model}

Figure 8 displays the average monthly discharges calculated from observed values and the RACMO2 runs. The simulated discharges for 2071-2100 are higher than the current discharges, but there is a large variability between the different RACMO2 runs. The original RACMO2 run overestimates the discharge, which is related to the temperature and precipitation bias. The difference between the two bias corrections is not very large. The MV bias correction estimates the discharge to be slightly higher than the WD bias correction. Summers are expected to become drier and the results on low flows seem to confirm this. The number of days with less than $60 \mathrm{~m}^{3} \mathrm{~s}^{-1}$ is higher for the RACMO2 runs than simulated for the control period 1969-1998.

The results of the discharge simulation runs with the HBV model are displayed in Table 3. Table 3 shows that the annual mean of the control period 1969-1998 is overestimated by all RACMO2 runs. The higher values are also visible in winter and summer half-year mean. The overestimation of the annual mean is similar for the WD bias correction method $(7 \%)$ and for the MV bias correction method (5\%). The difference in average precipitation between the observed values and both correction methods was less than $1 \%$. There are some factors that can play a role here. For example, the seasonal cycle of the precipitation in the RCM runs can be stronger, which results in lower soil moisture and reduced evaporation in summer. The MV and WD precipiation records show a slightly stronger seasonal cycle. The winters are a bit wetter and summers a bit dryer. Another indication for this is the lower frequency of wet days in summer for both bias correction methods compared to the observed percentage. A study for a Danish regime (van Roosmalen, 2009), which is comparable to the Meuse basins shows different results; 
Table 3. Statistics of the various HBV runs using observations (CTL) and uncorrected and corrected RACMO runs for the control and future periods. The HBV-CTL values reported in Table 1 are repeated here for comparison reasons.

\begin{tabular}{lcccccc}
\hline & HBV-CTL & RACMO2 & RACMO2 WD & \multicolumn{2}{l}{ RACMO2 MV } \\
& & uncorrected & & & & \\
\cline { 5 - 7 } & $1969-$ & $1969-$ & $1969-$ & $2071-$ & $1969-$ & $2071-$ \\
& 1998 & 1998 & 1998 & 2100 & 1998 & 2100 \\
\hline Annual mean $\left(\mathrm{m}^{3} \mathrm{~s}^{-1}\right)$ & 256 & 413 & 274 & 298 & 271 & 325 \\
No of days $\geq 1500 \mathrm{~m}^{3} \mathrm{~s}^{-1}(\%)$ & 0.4 & 1.4 & 0.2 & 0.3 & 0.3 & 1.5 \\
No of days $800<>1500 \mathrm{~m}^{3} \mathrm{~s}^{-1}(\%)$ & 4.5 & 13.6 & 4.6 & 9.0 & 4.9 & 11.5 \\
No of days $\leq 60 \mathrm{~m}^{3} \mathrm{~s}^{-1}(\%)$ & 15.7 & 7.3 & 13.5 & 25.7 & 15.1 & 26.7 \\
Maximal discharge $\left(\mathrm{m}^{3} \mathrm{~s}^{-1}\right)$ & 2836 & 3224 & 2384 & 2069 & 2868 & 3017 \\
Minimal discharge $\left(\mathrm{m}^{3} \mathrm{~s}^{-1}\right)$ & 8.4 & 29.6 & 23.8 & 3.2 & 18.5 & 2.8 \\
Winter half-year mean $\left(\mathrm{m}^{3} \mathrm{~s}^{-1}\right)$ & 329 & 546 & 354 & 433 & 347 & 478 \\
Summer half-year mean $\left(\mathrm{m}^{3} \mathrm{~s}^{-1}\right)$ & 182 & 412 & 194 & 161 & 194 & 169 \\
\hline
\end{tabular}

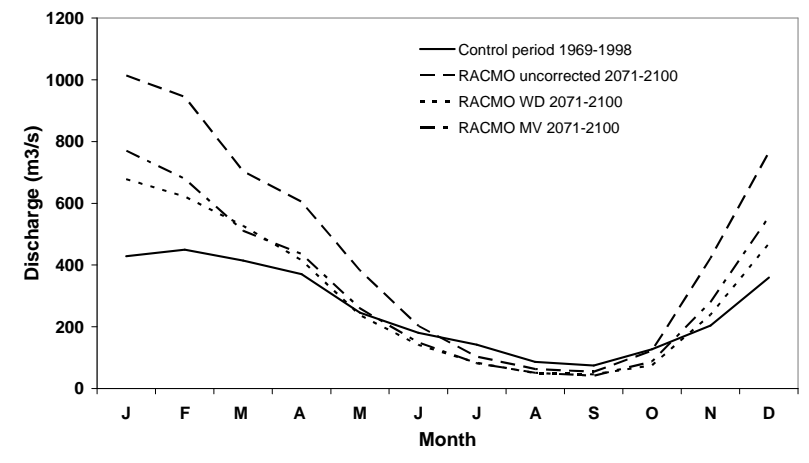

Fig. 8. Discharge at Borgharen calculated by the HBV model. The input was the observed precipitation and temperature values for the control period, as well as simulated precipitation and temperature values of the three RACMO2 runs.

the mean annua discharge after bias correction is only $1.6 \%$ larger than the observed. The table also shows that the number of days with more than $1500 \mathrm{~m}^{3} \mathrm{~s}^{-1}$ discharge is reduced by both bias correction methods. This indicates that extremes are not simulated accurately and could be underestimated.

In Table 3 the scenario period of both RACMO2 bias corrected runs are also shown. Both bias corrected runs show an increase of discharge for the simulated 30-year scenario period at the end of this century, compared to their control simulations. RACMO2 WD shows an increase of almost $9 \%$ between the future and control simulations. RACMO2 MV results in a much larger increase of $20 \%$. For the number of days above $1500 \mathrm{~m}^{3} \mathrm{~s}^{-1}$ the WD correction method shows only a small increase, while RACMO2 MV has a very large increase. Note however that Fig. 5 showed that the WD method overcorrects the number of successive precipitation days. This effect is also visible in the maximum discharge, which is considerably lower than the HBV-CTL maximum and the values of the other RACMO2 runs. The future scenario of RACMO2 WD even has a lower maximum than the present day climate. In Fig. 6, it was also shown that the MV method yields higher values for the 10-day precipitation amounts. This effect could result in a higher extreme discharge. The number of days with a moderately high discharge between $800 \mathrm{~m}^{3} \mathrm{~s}^{-1}$ and $1500 \mathrm{~m}^{3} \mathrm{~s}^{-1}$ is higher for both RACMO2 runs. Overall, in spite of the large differences, the RACMO2 data indicate that with the A1B scenario, used in the RACMO2 ECHAM5 run, the river Meuse will have substantial higher peak discharges at the end of this century.

Table 3 shows that the number of days below $60 \mathrm{~m}^{3} \mathrm{~s}^{-1}$ almost doubles for both bias corrected scenarios. The summer half-year mean decreases with almost $17 \%$ for the WD bias correction and with almost $13 \%$ for the MV bias correction method. This is consistent with the expectations of drier summers: the precipitation decrease for the WD method was $10 \%$ and for MV 7\%. As evaporation rates are much higher in the summer, it is expected that the decrease in discharge is higher.

\section{Discussion}

A problem with the use of RCMs for hydrological purposes is that the simulated precipitation differs systematically from the observed precipitation. This is observed in multiple studies (Jacob et al., 2007; Leander et al., 2007; Leander et al., 2008). Two different bias correction methods are used to correct the precipitation records. The results show large differences between these correction methods. The WD bias correction method shows almost no remaining bias in Fig. 4, but Fig. 5 shows that this method removes too many successive precipitation events. The HBV model hardly simulates extreme discharges with input of the WD bias corrected 
RACMO data. This makes the method less suitable for assessment of extreme discharges, where the MV method is recommended. Te Linde et al. (2009) also concluded that the WD method should be improved concerning extreme events. The monthly bias of the MV method is larger, but the average is simulated well and the standard deviation and $C V$ are simulated better than the WD bias correction method. The yearly maxima of the ten-day precipitation totals are well simulated.

For the WD bias correction the mean increase in winter discharge is $23 \%$, which is higher than the relative increase in precipitation. For summer discharge the decrease in discharge is $17 \%$, which is also higher than the relative decrease in precipitation. For the MV bias correction the same applies, with a mean increase in winter discharge of $38 \%$ and a mean decrease in summer discharge of $13 \%$. In winter the increase in precipitation is somewhat lower than the increase in discharge, which means that the water storage changes in the winter. In summer the decrease in precipitation is lower than the decrease in discharge due to increased evaporation rates in summer.

The maximum discharges of the WD bias correction are not higher than the maximum discharge of the historical period. This was expected, because the method corrected for the days with successive heavy rain, which is needed for high discharge. In Fig. 5 this is shown, the WD method has a lower maximum ten-day precipitation trend-line. The uncorrected and MV corrected discharge shows higher values than the observed period 1969-1998. This was expected from Fig. 6, which shows that the scenario period of MV has more successive rainy days than the period 1969-1998.

It is projected that winters will become wetter and extreme precipitation amounts will increase (KNMI, 2006). The results of this study, using a high resolution A1B RACMO2 scenario, show that HBV simulates higher discharges for the Meuse at the end of this century. This confirms results from previous studies on discharges (Booij, 2005; de Wit, 2001; de Wit et al., 2007b).

Only the SRES scenario A1B is used in this study and the results need to be confirmed by using a more comprehensive set of GCM simulations (Leander et al., 2008; Graham et al., 2007 ) as mean precipitation and changes in the $C V$ of 10-day precipitation amount are controlled strongly by the driving GCM.

The HBV model used in this study seems to have systematic biases, which result in over- or underestimations of the discharge. Research did point out that is not quite clear how well HBV can describe flood peaks (Booij, 2005; Leander et al., 2005). De Wit et al. (2007b) observed some deviations in the HBV model for the 1985-1998 record. The HBV model simulates monthly average discharges well for the months with the highest (January) and lowest (August) discharge, but they are generally overestimated during spring and underestimated during autumn. It also appears that in HBV most of the summer precipitation infiltrates the surface, whereas in reality summer precipitation often results in small but fast responses in river discharge. Leander et al. (2005) stated that the model does not consider the possibility of inundations upstream of Borgharen. This may limit the amount of water that can reach the Netherlands.

For the critical low discharge this research only partly confirmed the results of De Wit et al. (2007a). The HBV model simulates substantially more low flows for the end of this century. However, the HBV model overestimates the discharge in the summer period. Reason for this could be that refill from groundwater aquifers, to compensate for the reduced precipitation and increased evapotranspiration is overestimated by the HBV model. Another reason could be that the HBV model has problems with simulation of low flows. If the model is validated specifically against low-flow indices the performance could be improved (de Wit et al., 2007a).

The results of this study show that the use of a bias correction method can have a large influence on the simulated discharge. The bias correction generates an extra uncertainty, apart from other uncertainties that arise from for example model paramterization and downscaling techniques. The average discharge of the two bias-corrected runs differs from the discharge of the control period by 5 to $7 \%$. This uncertainty is further reinforced by the almost $10 \%$ variation between the results of the two bias correction methods for the scenarios periods. This paper emphasizes the importance of the use of an adequate bias correction and further research of the impact of bias correction methods.

The bias corrections are developed using data from the period 1969-1998 and are applied on the whole RACMO2 run of 1951-2100. Here the assumption is made that the corrections done for the historical period can also be applied to the period 1998-2100. The present climate variability is assumed to be the same for the scenario period. This assumption is uncertain as the variability of the future climate could be different from the present variability. The bias corrections done for the scenario period could for example reduce extremes. It is important that these methods are tested when more historical records are available.

Acknowledgements. Robert Leander and Alexander Bakker (KNMI) provided the codes for bias corrections and helped with questions about the codes. The temperature and precipitation data of the Meuse basin were provided by KNMI and by the Royal Meteorological Institute of Belgian for the Belgian. The HBV-96 model was provided by Deltares

Edited by: H. Madsen 


\section{References}

Aalders, P., Warmerdam, P. M. M., and Torfs, P. J. J. F.: Rainfall generator for the Meuse basin; 3000 year discharge simulations in the Meuse basin, Wageningen UR, 2004.

Ashagrie, A. G., de Laat, P. J., de Wit, M. J., Tu, M., and Uhlenbrook, S.: Detecting the influence of land use changes on discharges and floods in the Meuse River Basin - the predictive power of a ninety-year rainfall-runoff relation?, Hydrol. Earth Syst. Sci., 10, 691-701, 2006,

http://www.hydrol-earth-syst-sci.net/10/691/2006/.

Bakker, A. M. R. and Hurk van den, B.: Bias correction and resampling of RACMO output for the hydrological modelling of the Rhine, Royal Netherlands Meteorological Institute De Bilt, in press, 2009.

Bergström, S. and Forsman, A.: Development of a conceptual deterministic rainfall runoff model, Nord. Hydrol., 4, 147-170, 1973.

Bergström, S. and Carlsson, B.: River Runoff to the Baltic Sea, Ambio, 23, 280-287, 1994.

Bergström, S.: The HBV model, Water Resource Publications, 9, 443-476, 1995.

Bergström, S., Carlsson, B., Gardelin, M., Lindstrom, G., Pettersson, A., and Rummukainen, M.: Climate change impacts on runoff in Sweden-assessments by global climate models, dynamical downscaling and hydrological modelling, Clim. Res., 16, 101-112, 2001.

Booij, M. J.: Extreme daily precipitation in western Europe with climate change at appropriate spatial scales, Int. J. Climatol., 22, 69-85, 2002.

Booij, M. J.: Impact of climate change on river flooding assessed with different spatial model resolutions, J. Hydrol., 303, 176198, 2005.

Christensen, J. and Christensen, O.: A summary of the PRUDENCE model projections of changes in European climate by the end of this century, Climatic Change, 81, 7-30, 2007.

Diermanse, F. L. M.: HR2006 recalculation design discharge Rhine, Delft Hydraulics, Delft, the Netherlands, 2004 (in Dutch).

Graham, L., Hagemann, S., Jaun, S., and Beniston, M.: On interpreting hydrological change from regional climate models, Climatic Change, 81, 97-122, 2007.

Hagemann, S. and Jacob, D.: Gradient in the climate change signal of European discharge predicted by a multi-model ensemble, Climatic Change, 81, 309-327, 2007.

Van den Hurk, B., Albert, K. T., Lenderink, G., van Ulden, A., Oldenborgh van, G. J., Katsman, C., van den Brink, H., Keller, F., Bessembinder, J., Burgers, G., Komen, G., Hazeleger, W., and Drijfhout, S.: KNMI Climate Change Scenarios 2006 for the Netherlands, KNMI, De Bilt, 2006.

IPCC: Climate Change 2007: Synthesis Report, IPCC, 2007.

Jacob, D., Bärring, L., Bossing Christensen, O., Hesselbjerg Christensen, J., de Castro, M., Déqué, M., Giorgi, F., Hagemann, S., Hirschi, M., Jones, R., Kjellström, E., Lenderink, G., Burckhardt, R., Sánchez, E., Schär, C., Seneviratne, S. I., Somot, S., van Ulden, A., and van den Hurk, B.: An intercomparison of regional climate models for Europe: model performance in present-day climate, Climate Change, 81, 31-52, doi:10.1007/s10584-006-9213-4, 2007.
Jungclaus, J., Keenlyside, N., Botzet, M., Haak, H., Luo, J., Latif, M., Marotzke, J., Mikolajewicz, U., and Roeckner, E.: Ocean circulation and tropical variability in the coupled model ECHAM5/MPI-OM, J. Climate, 19, 3952-3972, 2006.

KNMI: Climate in the 21st century, four scenarios for the Netherlands, KNMI, De Bilt, 2006.

Leander, R., Buishand, T. A., Aalders, P., and de Wit, M. J. M.: Estimation of extreme floods of the River Meuse using a stochastic weather generator and a rainfall-runoff model, Hydrological Sciences, 50, 1089-1103, doi:10.1623/hysj.2005.50.6.1089, 2005.

Leander, R. and Buishand, T. A.: Resampling of regional climate model output for the simulation of extreme river flows, J. Hydrol., 332, 487-496, 2007.

Leander, R., Buishand, T. A., van den Hurk, B. J. J. M., and de Wit, M. J. M.: Estimated changes in flood quantiles of the river Meuse from resampling of regional climate model output, J. Hydrol., 351, 331-343, doi:10.1016/j.jhydrol.2007.12.020, 2008.

Lenderink, G., van den Hurk, B., van Meijgaard, E., van Ulden, A., and Cuijpers, H.: Simulation of present-day climate in RACMO 2: first results and model developments, KNMI, 2003.

Te Linde, A. H., Aerts, J. C. J. H., Bakker, A. M. R., and Kwadijk, J. C. J.: Simulating low probability peak discharge for the Rhine basin using resampled climate modeling data, Water Resour. Res., submitted, 2009.

Lorenz, P. and Jacob, D.: Validation of temperature trends in the ENSEMBLES RCM runs driven by ERA40, EMS8, 5, 2008.

Pfister, L., Kwadijk, J., Musy, A., Bronstert, A., and Hoffmann, L.: Climate change, land use change and runoff prediction in the Rhine-Meuse basins, River Res. Applic., 20, 229-241, 2004.

Roeckner, E., Bäuml, G., Bonaventura, L., Brokopf, R., Esch, M., Giorgetta, M., Hagemann, S., Kirchner, I., Kornblueh, L., Manzine, E., Rhodin, A., Schlese, U., Schulzweida, U., and Tompkins, A.: The atmospheric general circulation model ECHAM 5. Part I: Model description, Max Planck Institute for Meteorology, 2003.

van Roosmalen, L.: The effects of future climate change on groundwater en stream discharge in Denmark, PhD Department of Geography and Geology, University of Copenhagen, Copenhagen, 2009.

The HBV model: http://www.smhi.se/sgn0106/if/hydrologi/hbv. htm, 2007.

Smits, I., Wijngaarden, J., Versteeg, R., and Kok, M.: Statistiek van extreme neerslag in Nederland, STOWA, Utrecht, 2004.

Tu, M., Hall, M. J., de Laat, P. J. M., and de Wit, M. J. M.: Extreme floods in the Meuse river over the past century: aggravated by land-use changes?, Phys. Chem. Earth, 30, 267-276, $2005 \mathrm{a}$.

Tu, M., de Laat, P. J. M., Hall, M. J., and de Wit, M. J. M.: Precipitation variability in the Meuse basin in relation to atmospheric circulation, Water Sci. Technol., 51, 5-14, 2005b.

Uijlenhoet, R., de Wit, M. J. M., Warmerdam, P. M. M., and Torfs, P. J. J. F.: Statistical analysis of daily discharge data of the river Meuse and its tributaries (1968-1998): Assessment of drought sensitivity, Wageningen University and Research Centre, Wageningen, 2001.

van Schrojenstein Lantman, J.: Hoogwatervoorspellingen op de Maas in crisissituaties, Ministerie van Verkeer en Waterstaat, Twente, 2004. 
Warmerdam, P. M. M. and de Wit, M. J. M.: Climate change and low flows in the river Meuse, Wageningen, 2001,

De Wit, M. J. M.: Effect of climate change on the hydrology of the river Meuse, Wageningen UR, 2001.

De Wit, M. J. M., Uijlenhoet, R., Warmerdam, P. M. M., Torfs, P. J. J. F., Roulin, E., and Dewil, P.: Statistical analysis of discharge time series in the Meuse basin, Sustainable Use of Land and Water, 19th European Regional Conference of ICID, Brrno \& Prague, Czech Republic, 2001.
De Wit, M. J. M. and Buishand, A.: Generator of Rainfall And Discharge Extremes (GRADE) for the Rhine and Meuse basins, Rijkswaterstaat RIZA/KNMI, Lelystad, The Netherlands, 2007.

De Wit, M. J. M., van den Hurk, B., Warmerdam, P. M. M., Torfs, P. J. J. F., Roulin, E., and van Deursen, W. P. A.: Impact of climate change on low-flows in the river Meuse, Climate Change, 82, 351-372, 2007a.

De Wit, M. J. M., Buiteveld, H., and van Deursen, W. P. A.: Klimaatverandering en de afvoer van Rijn en Maas, RIZA, $2007 \mathrm{~b}$. 